\title{
DISCIPLINA, RACIONALIDAD Y MILITARISMO ROMANO. CLAVES PARA COMPRENDER ELEMENTOS CLÁSICOS EN LA CULTURA LATINOAMERICANA
}

Cecilia Ames

\begin{abstract}
RESUMEN
"Disciplina, racionalidad y militarismo romano" abren un espacio de reflexión que nos lleva directamente al tema de la cultura romana y su recepción moderna. Numerosos trabajos de sociólogos e historiadores, entre ellos los de Weber, Foucault y Elias, han mostrado la importancia de estos elementos clásicos para comprender la génesis y el desarrollo de la cultura moderna.

En esta línea de análisis y partiendo de la comprensión de estos conceptos claves en el De bello gallico de Julio Cesar, podemos precisar aspectos de la recepción de su discurso.

A partir de allí, y apuntando a la recepción latinoamericana, podemos reconocer elementos importantes y polémicos de nuestra propia cultura que se iluminan y aclaran de un modo especial cuando tenemos presente el paradigma romano.
\end{abstract}

El tema "La Cultura Clásica en América Latina" constituye, sin duda, una oportunidad para reflexionar sobre el lugar que ocupan los Estudios Clásicos en nuestra formación y en las discusiones actuales dentro del ámbito de las ciencias humanas, tanto históricas como sociales. Sin duda que en este momento, cuando se están cuestionando los planes de estudios de las carreras humanísticas y, ante el desprestigio y desinterés por estos estudios que observamos en nuestras universidades, resulta oportuno repensar qué espacio ocupan los Estudios Clásicos en general -y romanos en particular - y en qué medida este campo discipli-

Cecilia Ames. Universidad Nacional de Córdoba - CONICET. 
nar puede integrarse al planteo de problemáticas actuales y constituir un espacio de encuentro, de reflexión y crítica constructiva. De este modo, los Estudios Clásicos pueden constituirse en clave para comprender problemáticas modernas. Las investigaciones sobre la génesis de la Modernidad europea han mostrado que «disciplina», «racionalidad» y «militarismo» constituyen conceptos fundamentales para comprender el llamado -en palabras de Norbert Elias- "proceso de civilización" y el desarrollo del racionalismo occidental. El preguntarnos cuál es el aporte de la cultura romana a este proceso nos pone frente a la necesidad de profundizar el estudio de la práctica discursiva romana.

La Modernidad, sin duda, se ha valido de discursos, esto es, de temas, textos y autores "Clásicos" para formar sus ciudadanos disciplinados, sus obreros, sus soldados, sus políticos y militares. Durante mucho tiempo se consideró natural y obvia esta selección, que respondía al canon de la tradición occidental. Sin embargo, ahondar en la aparente y compleja paradoja Modernidad-Clasisismo nos lleva a plantear la cuestión en los términos de "estrategias de apropiación de la antigüedad" , abriendo perspectivas para el desarrollo de un humanismo crítico. Esta línea de investigación crítica y reflexiva, que ocupa un importante lugar en las investigaciones europeas y sienta las bases para toda discusión de planes de estudio, se desarrolló de un modo especial después de la segunda guerra mundial, cuando se ponen en tela de juicio los modelos transmitidos por los programas y textos universitarios y escolares y se profundiza en la investigación de la creación de símbolos y estereotipos nacionales modernos. Los Estudios Clásicos no quedaron fuera de la discusión y esto ha enriquecido la disciplina abriéndola a nuevas líneas de análisis. Una cita de P. Bourdieu aclara de modo ejemplar la apertura a nuevas perspectivas: "Si tal verso de Simónides atravesó toda la historia de Grecia, es precisamente porque era tan importante para el grupo que, al apropiarse de él, se apropiaba de un poder sobre el grupo. El intérprete que impone su interpretación no es solamente aquel que tiene la última palabra en una querella filológica, es también muy a menudo aquel que tiene la última palabra en la lucha política, quien apropiándose de la palabra pone el sentido común de su lado". ${ }^{1}$ Parafraseando a Bourdieu, podríamos decir que si un texto de los llamados clásicos, trátese de la Eneida de Virgilio o del de bello gallico de Julio César, por mencionar sólo un par de ejemplos, atravesó la historia europea moderna, formando parte de los planes de estudio de la mayoría de los establecimientos universitarios y escolares, esto es, si los modernos se apropiaron de ellos y su lectura fue obligatoria 
en las escuelas, era porque estos autores aún tenían algo que decir, algo importante para la formación del hombre moderno. Precisamente en uno de estos ejemplos nos vamos a detener, Julio César, pues la frase inicial de su obra Comentario a la Guerra de las Galias, Gallia est omnis divisa in partes tres, es algo que tienen en común todos los estratos de la población formada de Europa, lo que automáticamente a todos les hace recordar una etapa de su escuela secundaria.

Julio César, como autor de texto escolar, constituye un fenómeno digno de reflexión, pues César no fue ni durante la Antigüedad ni la Edad Media considerado escritor, sus textos no fueron usados en la educación de los niños ni se escribieron comentarios sobre ellos, a pesar de que muchos, entre ellos Cicerón, conocieron sus escritos y no dudaron en emular su competencia y su valor literario, caracterizado por su sobria elegancia. César, como escritor clásico, es un descubrimiento de la modernidad, ${ }^{2}$ la historia de la influencia y repercusión de sus escritos está completamente separada de la historia de su fama como político y militar. ${ }^{3}$ Julio César, así como en la Antigüedad conquistó la Galia, conquistó en la modernidad las escuelas. César fue sin duda un acontecimiento mundial, no sólo en la historia, sino también en la literatura, pues su Guerra de las Galias llegó a ser, a través de las escuelas, el bestseller de la literatura latina. Y esto sucedió no sólo en Francia, país para el cual esta obra constituye el primer documento literario de su historia, sino también para los demás países europeos. La frase acuñada por Opperman en 1958 "Preparador del camino hacia Europa" (Wegbereiter Europas $)^{4}$ no sólo coloca a César en la cercanía de Virgilio, "Padre de Occidente" , sino que cobra otra dimensión: ¿qué Europa es la que prepara?, pues ni los antiguos ni los medievales lo trataron como un preparador de occidente, y su lectura en las escuelas occidentales modernas es todo lo contrario a la continuación de una tradición "clásica". Quintiliano, que alaba los discursos de César, no dice una palabra sobre los commentarii. Un testimonio del siglo IV pone de manifiesto que los lectores de entonces se enteran de los sucesos de César por la obra de Tito Livio, ${ }^{6}$ autor que se leía en las escuelas. La antigüedad tardía casi no se ocupó de los comentarios de César. De un modo simptomático, la única excepción es más que elocuente: Orosio (s.V) incluye en su Historia adversus paga$n o s^{7}$ una extensa cita del de bello gallico, pero él cree que su autor es Suetonio. La Edad Media casi no conoció los comentarios y el nombre de César no se encuentra en ningún testimonio sobre la educación medieval. Una mirada a los programas de lectura de los siglos IX al XV de Francia, España y Alemania nos pone una vez más ante la ausencia. En 
Inglaterra la Guerra de las Galias permanece desconocida hasta el siglo XII. ${ }^{8}$ La primera traducción al francés de la Guerra de las Galias la realizó Carlos V (1364-1380), en 1597 aparece la primera traducción alemana y le siguieron las traducciones al inglés. ${ }^{9}$ Con respecto a la inclusión en los planes de estudio, la situación en Alemania resulta paradigmática: Recién en 1537 César fue introducido en el programa escolar de Estrasburgo, en 1575 en los colegios jesuitas, en 1580 en los colegios protestantes y a principios del S. XVII en la educación de los pietistas, abriéndose finalmente un camino que tendría largo alcance en casi todos los países europeos, ocupando un lugar preferencial sobre todo durante el s. XIX.

La historia de la influencia y repercusión de un texto romano del año 52. a.C. nos lleva así a la Modernidad. Entonces podemos preguntarnos: Qué afinidad tiene el de bello gallico de César con el espíritu de la Reforma y Contrareforma? El camino hacia qué Europa se prepara con la recepción de este texto en las escuelas? Las investigaciones sobre el surgimiento de la cultura moderna occidental, cuyo pionero fue Max Weber, han hecho del "disciplinamiento" un concepto fundamental. En sus observaciones breves y generales sobre la historia de la cultura investigó el significado de la disciplina y el poder de la disciplina racional, su relación con el carisma, el origen de este disciplinamiento en la disciplina militar y guerrera, su aplicación a Jas empresas económicas, especialmente en las grandes explotaciones, y su contribución a la internalización de las formas de dominio. ${ }^{10}$ Los trabajos de Norbert Elias, dedicados a la sociogenésis de la civilización occidental profundizan y enriquecen esta perspectiva y ha descripto el "proceso de la civilización" como el disciplinamiento de los guerreros feudales en las cortes, el dominio de los deseos de agresión, la contención de los instintos, la reglamentación de las costumbres. " Y sólo basta una lectura rápida de la obra de Foucault para percibir la importancia de la disciplina en la formación del hombre de la Modernidad, cuyos cuerpos dóciles y útiles han sido modelados en las escuelas, en el ejército, en los hospitales, en los talleres o en las fábricas, a través de la enseñanza y el ejercicio, de vigilancia y castigo, esto es, a través de disciplina. ${ }^{12}$

Si ahora volvemos a nuestro texto, la Guerra de las Galias, tenemos que preguntarnos: Qué contiene este texto que llevó a los hombre modernos a convertirlo en libro de lectura y ejercitación de sus futuros ciudadanos, soldados, trabajadores, clérigos? Los argumentos basados en lo interesante y motivador de sus aventuras para los jóvenes o los presupuestos didácticos de la simplicidad y claridad expresiva, que lo hace 
apropiado para estudiar latín en los primeros años, no bastan para explicar la intensidad y extensión temporal y espacial de su recepción. Los comentarios de César sobre la Guerra de las Galias no narran grandes aventuras ni constituyen novelas de héroes o matanzas sangrientas; en esta obra la guerra es presentada como un trabajo racional, ciencia, cálculo (scientia bellandi, ratio belli). Él comenta de un modo sencillo, claro y tendencioso un proceso político-militar: la romanización de toda la Galia; sus planes, medidas, acciones y sus "comentarios" sobre ellos están impregnados de racionalidad y disciplina militar y lingüística. Toda la Galia, términos con los que comienza la obra, es enseguida dividida en tres partes habitadas por diferentes pueblos. La política romana sabrá jugar con estas diferencias: divide et impera. La relación de César con el lugar donde él ha pasado ocho años de su vida, aparece en la primera frase como la del hacedor con su objeto, pero no un objeto literario; libre de emoción, la Galia es el objeto analítico, racional, militar. La Galia, es presentada como el protagonista desde la perspectiva del general que abarca todo con una mirada desde arriba, su presentación resume una expresión geográfica y un programa político. La visión general del teatro de operaciones no se interesa en los detalles geográficos o etnográficos. El terreno no es descripto sino dividido, las partes se enumeran y se nombran, los ríos son mencionados como divisores y límites. El lector queda sujeto desde el principio a ver la Galia con los ojos del general: el todo, pero dividido, y pronto, en el orden correspondiente, vencido y "pacificado", romanizado, este es el tema de la obra completa. También este principio es esclarecedor en cuanto al carácter de su obra, otorgándole un status excepcional dentro del tópico del género literario: a diferencia de los historiadores griegos y romanos, no explica sus patrones de medida, sus categorías o criterios, sino que los oculta bajo el manto de la pura facticidad. Desde la primera frase estamos frente a los hechos desnudos. A partir de allí nos sumergimos en el dinamismo del general y sus legiones, aún la geografía es descripta como acción, el terreno es incorporado a la acción. También el tiempo tiende a la acción, atrae el pasado y el tiempo de paz no se describe. Tratando de poner en orden las provincias romanas y por el honor del pueblo romano comienza el conflicto con los helvecios -una guerra que hay que legitimar-, a este conflicto fronterizo del sur de la Galia se le suman otro y otro más, formando una cadena ininterrumpida de guerras y acciones diplomáticas que terminan con la "pacificación" de toda la Galia. La lectura internaliza en el lector la máxima romana: si vis pacem, para bellum.

En la serie de guerras descriptas llama la atención que César no se 
detiene en la descripción de las batallas, ni en el comportamiento heroico y la valentía de sus soldados, el objeto que presenta no es la batalla en sí misma, sino la preparación y el cálculo; en esto radica la superioridad romana; además han internalizado la ratio rei militaris..$^{13} \mathrm{El}$ libro II nos brinda un claro ejemplo: el ejército de Cesar opera en el año 57 a.C. en Bélgica y de repente son atacados por los Nervios, que con increíble rapidez llegaron y se los veía aparecer por todos los costados. César tenía que hacer todo a la vez (BG II 20): enarbolar el estandarte, dar la senal de ataque, retirar a los soldados del trabajo, llamar a los que se habían alejado, formar el ejército, arengar a los soldados, dar la contraseña, mientras el tiempo para ello era escaso y el enemigo amenazaba continuamente. Pero ante esto dos cosas le ayudaban: la ciencia y práctica de sus soldados (scientia et usus) que los hacía tan capaces de dirigirse por las órdenes de otro como por su propia iniciativa, pues han internalizado táctica, orden y cooperación. Además de fortaleza (virtus), los romanos disponen de conocimiento (scientia) y de dominio de sí mismo, esto es, de disciplina. César no escatima los elogios que le merecen los bárbaros, sean galos o germanos, ellos son valientes y aman la libertad, sus acciones heroicas son reflejo de virtud, están acostumbrados a guerrear y aman las batallas y la fama. Los germanos, por el tipo de alimentación y las costumbres, son fuertes, de gran tamaño y se conducen con libertad, porque ellos desde la niñez no están acostumbrados al deber y a la disciplina (nullo officio aut disciplina adsuefacti) y no hacen nada en contra de su voluntad. ${ }^{14}$ Ellos son determinados y dominados por las pasiones, por la primera impresión, sus decisiones son imprevisibles, inconstantes, repentinas. Pero esta libertad de los germanos no condice con el sistema de valores construido por César en el texto, donde la libertad no se contrapone al deber y la disciplina. Además los bárbaros, ante los ojos de César, pueden ser héroes, pero no "soldados". De un modo paradójico, la valentía guerrera de los bárbaros es para César signo de su debilidad. La guerra, tal como César la presenta, no es un episodio heroico; ella significa sobre todo trabajo (labor): los legionarios deben caminar día y noche con pesado equipaje, establecer y levantar campamentos continuamente, desviar ríos, construir calles y puentes, levantar torres de asedio, sacar la nieve con palas, abrir zanjas, cavar galerías, pasar hambre, soportar los diferentes climas. Los soldados romanos trabajan siempre y soportan todo, en eso consiste la verdadera valentía. Ellos subordinan la voluntad individual al deber y la disciplina, que domina las pasiones y aplaza los deseos de satisfacción. ${ }^{15}$ Este psicograma del soldado romano, que parece el descripto por Foucault y Elias para el hom- 
bre moderno, es inculcado en los alumnos a través del trabajo con el texto. Claramente se lee en el texto la diferencia entre el alma salvaje y el alma civilizada. Dos imágenes de sociedad y de hombre son contrapuestos, galos y germanos son lo que los romanos no quieren ni deben ser: irracionales, desordenados, dubitativos, indisciplinados, desleales; a pesar de su amor a la libertad y la valentía, lo que César sabe apreciar, tienen que sucumbir ante la disciplina romana, la energía controlada y la fuerza de trabajo.

También el tiempo, el espacio y la naturaleza deben ser dominados por la racionalidad: organización, división de trabajos, dominio del espacio, problemas de comunicación, sincronización. Una pieza maestra sobre el lema "marchar separados, atacar juntos" encontramos en el libro V. La técnica domina la naturaleza y ayuda a superar las desventajas. Los pequeños romanos son más grandes que los monumentales cuerpos de los germanos, ellos pueden construir máquinas. La superioridad romana no se basa en la fortaleza corporal ni en la valentía, sino en organización, disciplina, técnica y propaganda. El excelente rendimiento del general y sus tropas tampoco necesita de la ayuda divina, los dioses están ausentes en su obra. Nuevamente en el libro II (cap. 29-30) encontramos una cita que grafica un modo ejemplar lo expuesto: los atuatucos se retiraron a una plaza extraordinariamente fortificada por la naturaleza, accesible sólo por un lado, donde colocaron un muro doble de gran altura. Desde el muro, vieron a los lejos levantarse una torre y se mofaban a voces de que a tanta distancia se levantara un aparato tan grande, preguntándose «con qué manos o con qué fuerzas, sobre todo unos hombres de tan corta estatura (pues generalmente todos los galos despreciaban nuestra pequeñez por ser ellos de gran tamaño) esperaban arrimar al muro una torre de tanto peso?». Pero cuando vieron que se movía y aproximaba a las murallas, aterrados por aquel nuevo y desusado espectáculo, enviaron a César emisarios diciendo que no creían que los romanos hicieran la guerra sin asistencia divina, pues podían hacer avanzar con tal rapidez máquinas de tal altura, por lo cual se entregaban en sus manos con todo cuanto tenían. La pintura de este suceso es más que elocuente, los bárbaros no ven el contexto terraplén-torre que los romanos han construido y piensan que los romanos están asistidos por los dioses. Las ventajas naturales de los atuatucos son superadas por la máquina romana. Los pequeños romanos son más grandes que los fuertes cuerpos, a través de técnica y disciplina vencen todas las desventajas de la naturaleza.

La planificación militar se corresponde con la planificación del tra- 
bajo que pronto se dejará ver en los grandes latifundios romanos, a los que los generales contribuirán con una cantidad nada despreciable de esclavos, que desplazará a los campesinos, que luchan en la Galia bajo las órdenes de César. ${ }^{16}$ Las victorias, sin duda, ofrecen grandes posibilidades económicas de explotación. De esta manera vemos la sincronización de producción y guerra y entendemos el concepto beweriano de la aplicación del disciplinamiento militar a las empresas económicas; la lectura de las hazañas de César ha contribuido a introducir a las elites occidentales en esa tradición.

La cultura romana , transmitiendo su racionalidad jurídica al derecho canónico y civil de occidente, ha acuñado nuestra manera de pensar y de hablar. Ella, además, nos ha transmitido los términos racionalidad, militarismo, disciplina, ejercitar, desertar, capitular, y ha enriquecido nuestro vocabulario con sentencias: divide y reinarás; si quieres la paz, prepara la guerra; llegué, vi y vencí. Historiadores y escritores, no sólo europeos sino también latinoamericanos, nos han transmitido el modelo del legionario valiente y disciplinado y del cauteloso, sensato y exitoso general que supera la barbarie indisciplinada. La Guerra de las Galias ocupa en esto un lugar preferencial, su desarrollada inteligencia militar la hizo útil a la burguesía y el absolutismo del Renacimiento y de la Edad Moderna; el texto ofreció otros aspectos caros al mundo moderno: legitimación de la guerra de conquista, colonización, imperialismo, y se instala en una tradición educativa que no será cuestionada hasta bien entrado nuestro siglo. Las escuelas han divertido a los niños con esas hazañas, $y$, de ese modo, ellos recibían inconscientemente su racionalismo militar y su disciplina a través de la clase de historia y del estudio y ejercicio de la sintaxis oracional en la clase de latín. Ahora nos resulta clara la observación de Foucault: Roma ha transportado a la modernidad no sólo el ideal jurídico de la ciudadanía, sino también la técnica de los procedimientos disciplinarios, cuyo modelo fue la legión romana, pues Roma, bajo su faz militar, era el esquema ideal de la disciplina.

En Latinoamérica, continuando esa tradición, los Estudios Clásicos ocuparon un lugar preferencial en muchos momentos de nuestra historia. Con las transformaciones múltiples que trajo consigo la democracia, vino otra propuesta de transformación: sustituir los Estudios Clásicos, considerados lejanos, extraños y ajenos a nosotros y, además, asociados sólo al imperialismo y militarismo, e introducir en lugar de ellos más estudios de Cultura Popular. Para nosotros representa hoy un desafío mostrar cuántos elementos aportan los Estudios Clásicos para comprender también nuestra propia historia, nuestra educación, introducida 
especialmente por los jesuitas, nuestros conceptos de civilización y barbarie y la construcción de nuestros héroes nacionales. ${ }^{17}$ En efecto, el binomio civilización-barbarie, título de la obra que Sarmiento publicó en 1845 , atraviesa toda la historia latinoamericana, no sólo como representación literaria, sino como lectura social de la realidad. Las sucesivas transformaciones y relecturas de la dicotomía sarmientina nos pueden servir de hilo conductor en un itinerario por la historia argentina y por la escritura de su historia. ${ }^{18}$ El nacimiento de la historiografia argentina y la definición del modo de escribir historia, especialmente la obra de Mitre y su construcción de los héroes San Martín, Belgrano y Güemes, ${ }^{19}$ nos remite también a un modelo clásico. Y todo ello se ilumina de un modo especial si comprendemos la práctica romana, su discurso y la intensidad de su recepción, pues ocupa un lugar importante en la producción de sentidos y representaciones que serán receptadas por agentes sociales latinoamericanos que interpretan desde sus propias condiciones objetivas. Así, desde marcos teóricos actuales podemos volver a los Estudios Clásicos.

De esta manera, intenté exponer en un ejemplo cómo, en lugar de eliminar los Estudios Clásicos, podemos potenciarlos con nuevas perspectivas: analizar en la construcción discursiva las transformaciones que se operan en el ámbito de la ratio y la disciplina militaris, lo que se muestra interesante a la antropología histórica y a la sociología del poder, y reflexionar sobre el lugar de su recepción en el proceso de desarrollo de la Europa moderna. A partir de allí, rastrear la introducción de estos modelos en los nacientes estados latinoamericanos y su contribución a nuestra cultura, incluso a la cultura popular, se plantea como una interesante tarea para un humanismo crítico, que, de este modo, puede contribuir a que los Estudios Clásicos ocupen un lugar importante en nuestra formación y constituyan un espacio de reflexión y encuentro.

\section{BIBLIOGRAFÍA}

ADCOCK, F., Caesar als Schriftsteller, Vandenhoeck \& Ruprecht, Göttingen 1958 .

CANCIK, H., Rationalität und Militär - Caesars Kriege gegen Mensch und Natur, en: Lateinische Literatur, heute wirkend II, Göttingen 1986.

COLLINS J.H., Caesar as Political Propagandist, ANRW I 1, p. 922-966.

CHRIST, Karl, Caesar. Annährungen an einem Diktator, München 1994. 
GLÜCKLICH, H. J., Soldaten für Caesar. Vier Szenen aus den "Commentarii", AU 33,5 (1990) p. 74-81.

GÖRLER, W., Caesar als Erzähler (am Beispiel von BG II 15-17), AU 23,3, (1980) p. 18-31.

HARMAND, J., Une composante scientifique du Corpus Caesarianum: le potrait de la Gaule dans le "de bello gallico" I-VII, ANRW I 3, p. 523-595.

KROIMANN, J., Cesar und das Corpus Caesarianum in der neuren Forschung, ANRW I, 3, 1973, p. 457 ss.

LATACZ, J., Zu Cäsars Erzählstrategie (BG I 1-29), AU 21,3 (1978), p. 70-87.

LOHMAN, D., Leserlenkung im Bellum Helveticum, AU 33,5 (1990) p. 56-73.

MENSCHING, E., Caesars bellum Gallicum. Eine Einführung, Frankfurt am Main 1988.

PASCUCCI, G, Interpretazione linguistica e stilistica del Cesare autentico, ANRW I 3, p. 488-522.

RADITSA, L., Julius Caesar and his Writings, ANRW I 3, p. 417-456.

RAMBAUD, M., L'art de la déformation historique dans les Commentaires de César, 2.de., Paris 1966.

RICHTER, W., Caesar als Darsteller seine Taten, Heildelberg 1977

RÜPKE, J., Wer las Caesars bella als comentarii?, Gymnasium 99 (1992) p. 201 226. 1990.

Domi Militiae. Die Religiöse Konstruktion des Krieges in Rom. Stuttgart

Gerechte Kriege - gerächte Kriege, AU 5 (1990), p. 5-13.

SIEBENBORN, E., Bellum Iustum, AU 33,5 (1990) p. 39-55.

TIMPE, D., Caesar gallischer Krieg und das Problem des römischen Imperialismus, Historia 14 (1965), p. 189-214.

VOGT, J., Caesar und seine soldaten, en: Orbis. Ausgewählte Schriften zur Geschichte des Altertums, Freiburg 1960, p. 89-109.

\section{NOTAS}

1. P. Bourdieu, Cosas Dichas, Gedisa, Buenos Aires, 1998, p. 117.

2. W. Richter, Caesar als Darsteller seiner Taten, Heidelberg 1977, esp. Cap. 1: Caesar als Schulschiftsteller, p. 7-23.

3. R. Gundolf, Caesar, Geschichte seines Ruhmes, Berlin 1924.

4. H. Oppermann, Caesar, Wegbereiter Europas, Göttingen/Berlin/Frankfurt a.M. 1958. 
5. Th. Haecker, Vergil, Vater des Abendlandes, Frankfurt a.M. 1948 (hay traducción española).

6. Symmachus, epist. 4,18,5 (Mon. Germ.auct.ant. VI 1 P.104).

7. VI 7-11.

8. J.D.A. Ogilvie, Books known to Englisch , 1967, 103.

9. S.G. Highet, The Classical Tradition, 1964, 117 (hay traducción española).

10. M.Weber, Economía y Sociedad, F.C.E., México 1944 (1922), esp. II 882 ss.

11. N. Elias, El Proceso de la Civilización, F.C.E., México $1989(1977,1979)$.

12. M. Foucault, Vigilar y Castigar, Siglo XXI Ed. 1976 (1975), esp. 139 ss.

13. H. Cancik, Rationalität und Militär -Caesars Kriege gegen Mensch und Natur, en: Lateinische Literatur, heute wirkend II, Göttingen 1987, 7-29.

14. Cfr. BG IV 1: a pueris nullo officio aut disciplina adsuefacti nihil omnino contra voluntatem faciunt.

15. Cuando los bárbaros se conducen con disciplina, es porque ha aprendido de los romanos, por eso Espartaco (73-71 a.C.) pudo resistir tanto tiempo. Cesar destaca la capacidad de los bárbaros para imitar y practicar las invenciones de otros (VII 22). Cfr. También VII 30; la gente, que no estaba acostumbrada a esos trabajos (para la fortificación del campamento) quedó tan consternada, que pensaban que debían hacer y soportar todo lo que se les ordenaba.

16. H. Cancik, Disziplin und Rationalität. Zur Analyse militärischer Intelligenz am Beispiel von Caesars "Gallischem Krieg", Saeculum XXXVII, 1986, 166-181.

17. Cfr. D.T. Mozejko de Costa, La construcción de los héroes nacionales, Estudios $\mathrm{N}^{\circ} 6$ (Centro de Estudios Avanzados de la Universidad Nacional de Córdoba) 1996, p. 79-82.

18. Cfr. M. Svampa, El dilema argentino: Civilización o Barbarie. De Sarmiento al revisionismo peronista, Buenos Aires, 1994.

19. Cft. R. Costa y D.T. Mozejko, Los Güemes en la historia o modos de hacer historia, Escribas, $N^{\circ}$ Presentación (Revista de la Escuela de Letras. Universidad Nacional de córdoba) 2000, p. 107-135. 